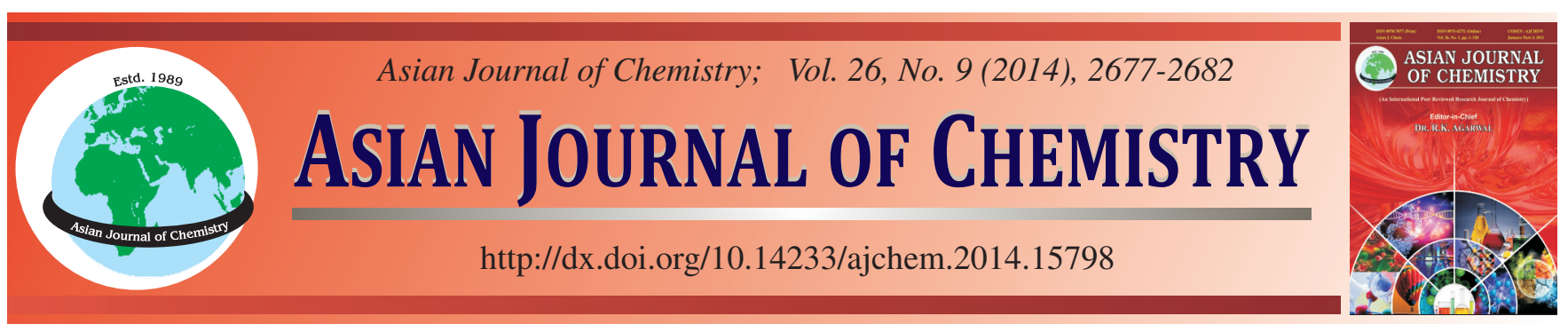

\title{
Effects of Continuous Volume Extensional flow on Low Density Polyethylene/Calcium Carbonate Nanocomposites
}

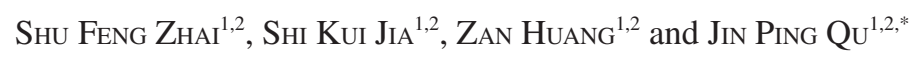

${ }^{1}$ The National Engineering Research Center of Novel Equipment for Polymer Processing, P.R. China

${ }^{2}$ The Key Laboratory of Polymer Processing Engineering of Ministry of Education,South China University of Technology, Guangzhou 510640, Guangdong, P.R. China

*Corresponding author: Fax: +86 20 87112503; Tel: +86 20 87112803; E-mail: jpqu@ scut.edu.cn; 8959422@163.com

\begin{abstract}
In this paper, low density polyethylene (LDPE)/calcium carbonate $\left(\mathrm{CaCO}_{3}\right)$ nanocomposites were prepared both by Battenfeld screw extruder and vane extruder which is a kind of innovative equipment for polymer processing. Effects of the two processing equipment on the morphology, the thermal behaviour and the mechanical properties of the composites were investigated by scanning electron microscopy, differential scanning calorimetry (DSC), wide-angle X-ray diffraction and mechanical testing. SEM examinations showed that the nanocomposites extruded in the vane extruder had a smaller particle diameter and better effects on the distribution and dispersion mixing, compared with those extruded by the screw extruder. Correspondingly, it exhibited a higher degree of crystallinity, which was determined by DSC. Both the tensile and flexural properties of $\mathrm{LDPE} / \mathrm{CaCO}_{3}$ nanocomposites extruded by the vane extruder are much higher than that extruded by the screw extruder.
\end{abstract}

Keywords: Volume extensional flow, Vane extruder, Nanocomposites, Dispersion.

\section{INTRODUCTION}

Polymer nanocomposites represent an interesting topic both in the materials science and engineering due to their promising properties ${ }^{1,2}$. It is well known that the dispersion of inorganic particles within polymer matrix significantly influences the mechanical properties of the composites ${ }^{3}$. As for polymer nanocomposites, the particle size of the dispersed phase should have at least one dimension in the range of less than 1-100 $\mathrm{nm}^{4}$. To achieve this scale of dispersed phase, many researches published papers ${ }^{5-7}$. It has been proved that a good dispersion strongly depends on the processing conditions. One of the approved views is to introduce strong shear stress in polymer processing. Based on this theory, there have been many facilitates such as various shearing elements and kneading blocks installed to the conventional screw extruder ${ }^{5}$, novel multi-stage-mill mixer, ultra-high-speed mixer ${ }^{4}$ and lots of sonic assisted equipment ${ }^{6,7}$ etc. Relative researches have proved that these facilitates can greatly improve the state of dispersion. However, degradation of polymer molecular, consumption of energy and inferior effect of dispersion simultaneously eclipsed the tiny positive effect.

The mixing theory suggests that the dispersion of solid particles would be four times more efficient in an extensional flow than in a shear field. It shows that the extensional flow has better effects on the dispersive and distributive mixing ${ }^{8}$. These facts lead researchers to develop polymer processing equipment based on extensional flow field. One of the representations is the extensional flow mixer (EFM), which generate extensional flow through the C-D plates ${ }^{9}$. The relative results showed compounding PA-6 with C15A in a single-screw extruder with EFM-N produced nanocomposites with high performance. Other works focussing on the extensional flow field are generally convergent dies with different profile, such as cone, hyperbolic and parabolic shape ${ }^{10}$. All of this facilitates based on extensional flow have shown good dispersibility and thus better performance of the prepared composites. However, all of these equipment based on extensional flow are limited and intermittently. In another word, they cannot work without the screw extruder. Therefore, the advantages of extensional flow are severely hindered from bringing into full play.

The vane extruder ${ }^{11,12}$ realizes a continuous volume extensional flow field via the convergence and divergence of the volume. It can be applied to the polymer processing without any other auxiliary facilitates. In this paper, we briefly discuss first the structure schematic diagram of the novel vane extruder and how it generates those flows. Secondly, what were focused on is that the effects of the continuous volume extensional 
flow field on the morphology and mechanical properties of $\mathrm{LDPE} / \mathrm{CaCO}_{3}$ nanocomposites. For the sake of comparison, these composites are also prepared by the conventional screw extruder under the same processing parameters.

Flow field in vane extruder: The schematic diagram of the structure of vane extruder is shown in Fig. 1. The vane extruder consists a number of groups of vane plasticating and conveying units (VPCU). Every group of the VPCUs is composed of a stator, a rotor, four vanes and two baffles. The rotor is eccentrically installed in the intra-cavity of the stator. The four vanes are installed in pairs in the rectangular through hole of the rotor. The bottom surface of the paired vanes makes contact with each other. When the rotor is rotating, the pair of vanes makes reciprocating movement through the radial rectangular through hole of the rotor because of the action of the inner surface of the stator. The two baffles are the discharge and feed baffles, which are used to discharge and feed materials, respectively. In the vane extruder, the discharge baffle of the front group of VPCU is the feed baffle of the next one. In two adjacent groups of VPCU, the eccentric directions of the rotor are opposite. Moreover, to reduce the discharge fluctuation, the locations of the vanes change to an angle of $45^{\circ}$ in two adjacent groups of VPCU.

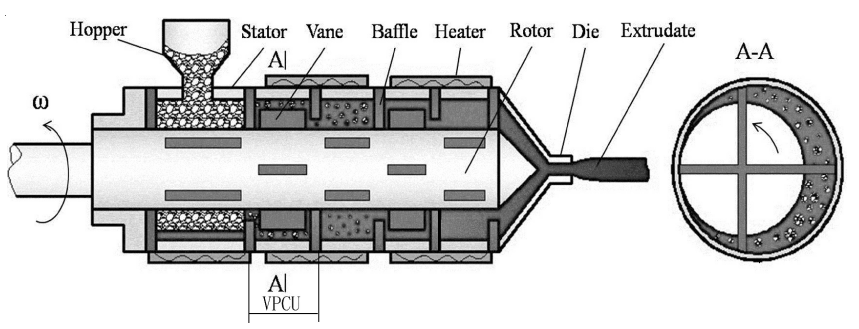

Fig. 1. Schematic diagram of the vane extruder

In one group of VPCU, the space between the stator and the rotor are divided into four cavities by four vanes. The motion of the materials in the four cavities is the same when the rotor rotates a circle. Therefore, as shown in Fig. 2(a), it is only needed to describe the motion of the materials in one cavity. When the rotor is rotating, it will generate a periodic changing of the volume of the cavity. The cavity feeds materials from the front one group of VPCU through the feed baffle when the volume increases. It discharges materials to the next one group of VPCU through the discharge baffle when the volume decreases. The flow in one group of VPCU can be simplified to a forced convergence flow, shown in Fig. 2(b). If there are no vanes, it can only generate a little convergence extensional flow because of the dragging of the rotor. However, if there are vanes, it will generate a compulsory push on the materials. When the rotor dragging and the vane pushing the materials go through the wedged-grooves, it will generate a large volume extensional flow. In the discharge process, the vane acting on the materials generates a convergent extensional flow and in the feed discharge process, it generates a divergent extensional flow. With continuous connecting of the discharging outlet of the front group of VPCU with the feeding inlet of the next group, a continuous volume extensional flow is produced.

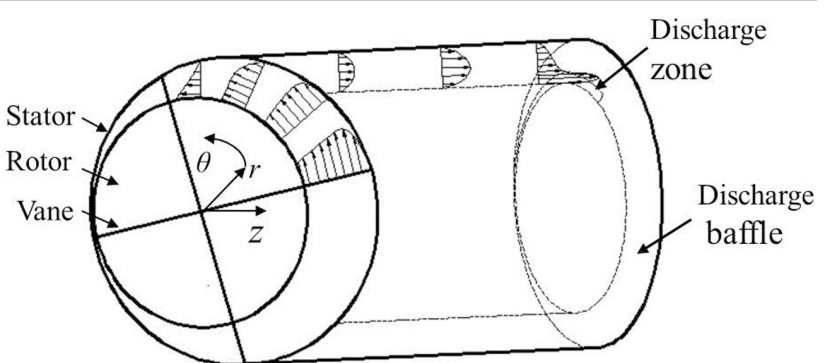

(a)

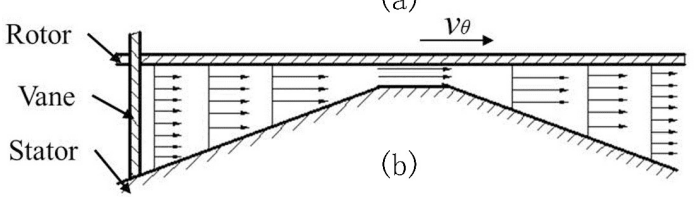

Fig. 2. Structure schematic diagram of the motion of the materials in one VPCU

The structure schematic diagram of the two adjacent groups of VPCU is showed in Fig. 3. Fig. 3 (a) shows the state of the second group of VPCU, in which the rotor is eccentric to the left and the vanes are placed levelly and vertically separately. Fig. 3(b) shows the state of the third VPCU, in which the rotor is eccentric to the right and the vanes are placed in the position of angle of $45^{\circ}$ with the level line. The discharge zone of the second VPCU is just right the feed zone of the third VPCU. When the rotor is rotating, the materials in the cavity $A_{1}$ will go into the cavity $B_{1}$ and the cavity $B_{2}$ because of the different positions of the vanes in the two adjacent VPCUs. This flow is similar to the chaotic flow in the chaotic screw. The chaotic screw uses the parts in the screw channel to divide the continuous flow and generates a chaotic flow. Therefore, it can generate a local chaotic flow in the position of the baffles.

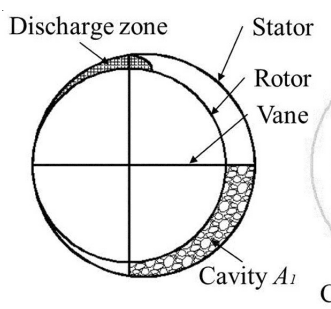

(a) Second VPCU

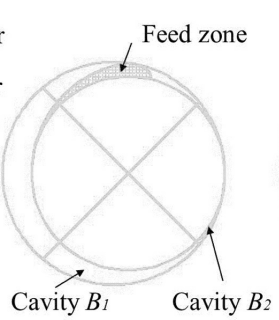

(b) Third VPCU

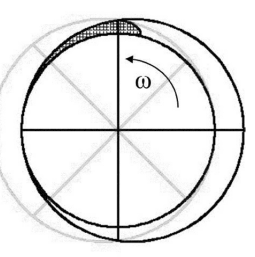

(c) Adjacent VPCUs
Fig. 3 Structure schematic diagram of the motion of the materials in two adjacent VPCUs

In a word, the motion of the materials in the flow field of the vane extruder is rather complex. It not only has continuous flow in one cavity of the VPCU but also dis-continuous flow between the two adjacent VPCUs. The continuous flow in the cavity is a complicated three-dimensional flow and continuous volume extensional flow. The dis-continuous flow is the chaotic flow in the two adjacent VPCUs. In this way, it can generate a continuous convergent-divergent extensional flow and a local chaotic flow in the vane extruder.

\section{EXPERIMENTAL}

The materials used in this paper were filmy-grade LDPE with trade mark of $1810 \mathrm{D}$, supplied by Petrochem. Co 
(Guangzhou, China). The resin density in solid state is 0.920 $\mathrm{g} / \mathrm{cm}^{3}$ and the melt flow index is $0.25 \mathrm{~g} / 10 \mathrm{~min}$ (ASTM D1238). The filler used in this work was a nanometer calcium carbonate master batch (nano- $\mathrm{CaCO}_{3}$ ), prepared by Guofeng zhijia plastic and elastomer materials company (Guangdong, China). Specifications of the product were shown in Table-1.

\begin{tabular}{lc}
\multicolumn{2}{c}{ TABLE-1 } \\
\multicolumn{2}{c}{ SPECIFICATIONS OF THE NANOMETER } \\
CALCIUM CARBONATE MASTER BATCH \\
\hline \multicolumn{1}{c}{ Properties } & Parameters \\
\hline Content of nano- $\mathrm{CaCO}_{3}(\%)$ & 75 \\
Diameter of nano- $\mathrm{CaCO}_{3}(\mathrm{~nm})$ & $13-30$ \\
Density $\left(\mathrm{g} / \mathrm{cm}^{3}\right)$ & 1.9 \\
$\mathrm{MI}(\mathrm{g} / 10 \mathrm{~min})$ & 15 \\
\hline
\end{tabular}

General procedure: The nano- $\mathrm{CaCO}_{3}$ master batch was dried at $85{ }^{\circ} \mathrm{C}$ for $4 \mathrm{~h}$, then premixed with LDPE at $0 / 100$, $5 / 95,102 / 90,15 / 95,20 / 80$ ratios by weight in a high speed mixer for $5 \mathrm{~min}$. The pre-mixture was extruded by the vane extruder and the Battenfeld screw extruder with a rotator speed of $120 \mathrm{rpm}$. The barrel temperatures were, respectively 150 , 190,190 and $190{ }^{\circ} \mathrm{C}$. Then, the extrudates were pelleted by the granulate equipment. It was called as the vane samples extruded by the vane extruder, accordingly, the others were the screw samples. The vane extruder had 19 groups of VPCUs. The diameter of the rotor was $\varphi 40 \mathrm{~mm}$ and the ratio L/D of the effective length to the diameter was 10 for the vane extruder, whereas it was $\varphi 45 \mathrm{~mm}$ and 25 for the screw extruder. Though might not make the geometric parameters totally uniform, it could give a trend of the two kinds of the polymer processing machines. After being dried at a temperature of $85^{\circ} \mathrm{C}$ for $4 \mathrm{~h}$, the filled pellets were hot-pressed at $200^{\circ} \mathrm{C}$ under a pressure of $10 \mathrm{MPa}$ for $6 \mathrm{~min}$ using a flat-plate sulfide machine (Wuxi No. 1 Rubber and Plastics Plant, Wuxi, China, model QLB$25 \mathrm{D} / \mathrm{Q})$ to obtain testing samples. Sheets of $1 \mathrm{~mm}$ and $4 \mathrm{~mm}$ thickness were prepared.

Detection method: A Philip XL-30 scanning electron microscope (SEM) was used to observe the morphology of the nanocomposites. Samples were brittle fractured in liquid nitrogen and the fracture surfaces were sputtered with gold. A NETZCH DSC204 was used to examine the crystallinity of the nanocomposites. The samples were heated from $25-200{ }^{\circ} \mathrm{C}$ with a heating rate of $10{ }^{\circ} \mathrm{C} / \mathrm{min}$ in a nitrogen atmosphere and held there for $5 \mathrm{~min}$ to completely eliminate any possible crystallinity or residual stresses in the samples. Then samples were cooled from 200 to $25^{\circ} \mathrm{C}$ to probe the crystallization temperature $\mathrm{T}_{\mathrm{c}}$ and held there for $3 \mathrm{~min}$. The temperature was ramped back up to $200{ }^{\circ} \mathrm{C}$ with a heating rate of $10^{\circ} \mathrm{C} / \mathrm{min}$ to probe the melting point $\mathrm{T}_{\mathrm{m}}$ after crystallization.A BRUKER D8GADDS X-ray diffractometer was used for a wide-angle $\mathrm{X}$-ray diffraction (WAXD) study. A 40-kv accelerating voltage and a $30 \mathrm{~mA}$ current were applied using $\mathrm{CuK}_{\alpha}$ radiation. WAXD intensities were recorded from $2 \theta=10$ to $2 \theta=70$ in transmission mode on samples at a scan step of 0.02. An Instron 5566 tensile testing machine was used to examine the mechanical properties of the nanocomposites. Before the test, the molded sheets were machined into standard samples for tensile and flexural testing.

\section{RESULTS AND DISCUSSION}

Figs. 4 and 5 show SEM micrographs of brittle fracture surfaces of the $\mathrm{LDPE} / \mathrm{CaCO}_{3}$ nanocomposites samples with a nano- $\mathrm{CaCO}_{3}$ weight content of $3.75 \%$ prepared both by the vane and screw extruders. The calcium carbonate particles in the vane samples are much smaller than that in the screw samples. Moreover, it can be seen that the particles in the vane samples is better distributed than that in the screw samples. It shows that the $\mathrm{CaCO}_{3}$ particles agglomerate in the screw extruder. However, it is not seen the agglomeration phenomenon in the vane extruder. It indicates that the continuous volume extensional flow and local chaotic flow generated in the vane extruder have good effects on the dispersion and distribution mixing for the polymer/inorganic particle nanocomposites.
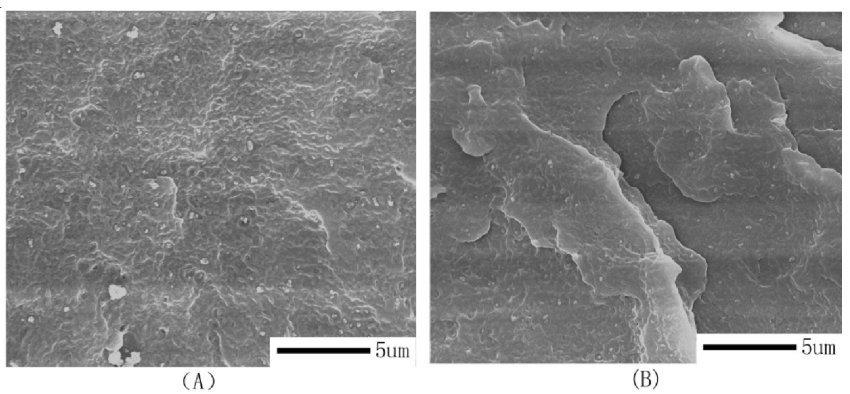

Fig. 4. SEM photographs for 3.75\% LDPE/ $/ \mathrm{CaCO}_{3}$ nanocomposites (×20000) (A) Screw samples; (B) Vane samples
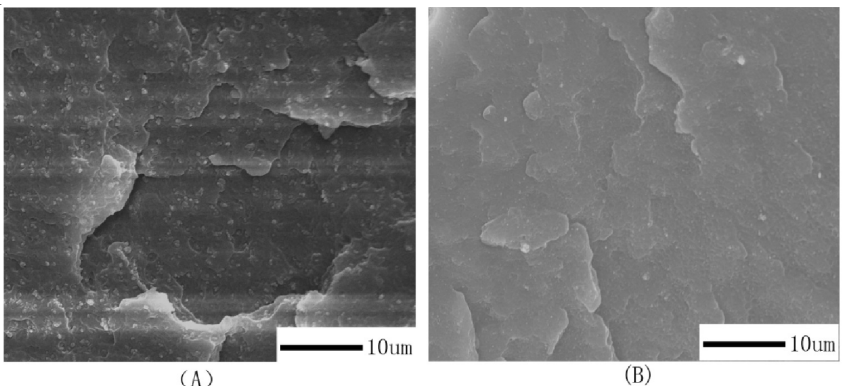

Fig. 5. SEM photographs for $3.75 \% \mathrm{LDPE} / \mathrm{CaCO}_{3}$ nanocomposites (×5000) (A) Screw samples; (B) Vane samples

Thermal behaviour: Figs. 6 and 7 show the DSC curves of pure LDPE and its nanocomposites of the vane samples. Table-2 shows the DSC characteristics of LDPE and its nanocomposites of both the vane and screw samples. It can be seen that the crystallization temperature $\left(\mathrm{T}_{\mathrm{c}}\right)$ of the pure LDPE are 93.3 and $92.4^{\circ} \mathrm{C}$, respectively for vane samples and screw samples. For nano- $\mathrm{CaCO}_{3}$ content of $3.75 \%$, the $\mathrm{T}_{\mathrm{c}}$ of the vane samples is $96.1{ }^{\circ} \mathrm{C}$, while it is $92.6{ }^{\circ} \mathrm{C}$ for the screw samples. In other words, both the $\mathrm{T}_{\mathrm{c}}$ of pure LDPE and its nanocomposites extruded by the vane extruder are higher than that extruded by the screw extruder. It means that the vane samples can crystallize in high temperature.

The melting temperature $\left(\mathrm{T}_{\mathrm{m}}\right)$ of the pure LDPE of the vane samples and screw samples are 112.8 and $111.4{ }^{\circ} \mathrm{C}$, respectively. The $\mathrm{T}_{\mathrm{m}}$ of the vane samples with a nano- $\mathrm{CaCO}_{3}$ weight content of $3.75 \%$ is $110.1{ }^{\circ} \mathrm{C}$, whereas it is $111.7^{\circ} \mathrm{C}$ for the same screw samples. It can be seen that for the pure LDPE, the $T_{m}$ of the vane samples is higher than the screw samples. However, the $\mathrm{T}_{\mathrm{m}}$ of the $\mathrm{LDPE} / \mathrm{CaCO}_{3}$ nanocomposites 


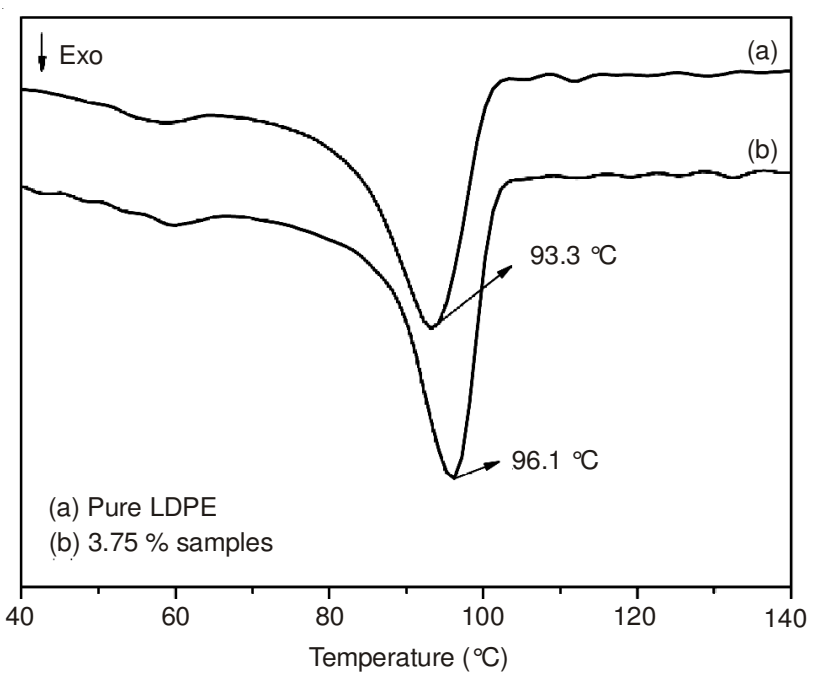

Fig. 6. DSC curves of crystal behaviour of $\mathrm{LDPE} / \mathrm{CaCO}_{3}$ nanocomposites prepared by vane extruder

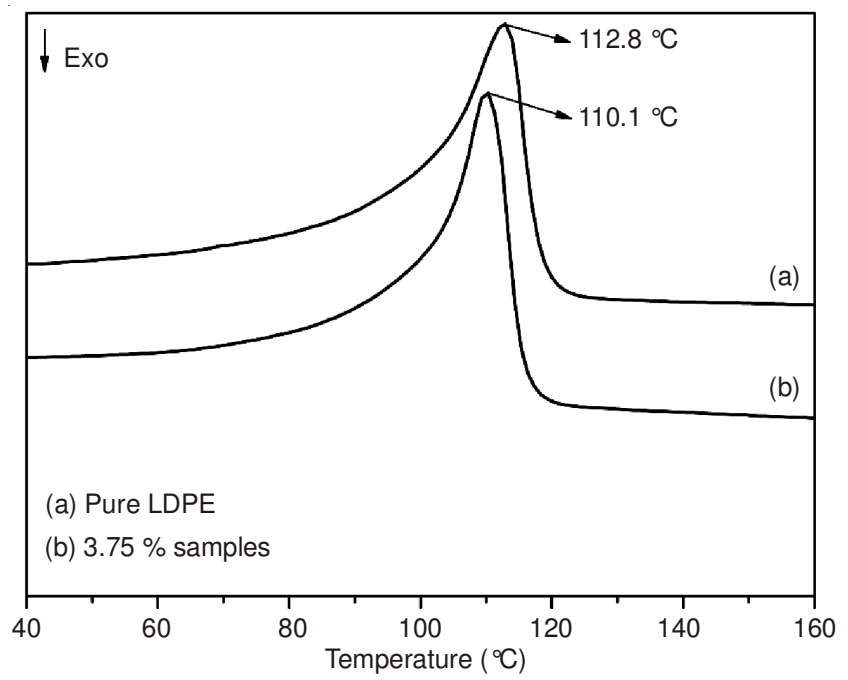

Fig. 7. DSC curves melting behaviour of $\mathrm{LDPE} / \mathrm{CaCO}_{3}$ nanocomposites prepared by vane extruder

\begin{tabular}{ccccccc}
\multicolumn{7}{c}{ TABLE-2 } \\
DSC CHARACTERISTICS OF LDPE/CaCO \\
\multicolumn{5}{c}{ NANOCOMPOSITES } \\
PREPARED BY THE VANE AND SCREW EXTRUDERS \\
\hline $\begin{array}{ccccccc}\text { Content } \\
(\%)\end{array}$ & $\begin{array}{c}\mathrm{T}_{\text {on }} \\
\left({ }^{\circ} \mathrm{C}\right)\end{array}$ & $\begin{array}{c}\mathrm{T}_{\mathrm{c}} \\
\left({ }^{\circ} \mathrm{C}\right)\end{array}$ & $\begin{array}{c}\mathrm{T}_{\mathrm{m}} \\
\left({ }^{\circ} \mathrm{C}\right)\end{array}$ & $\begin{array}{c}\Delta \mathrm{H} \\
(\mathrm{J} / \mathrm{g})\end{array}$ & $\begin{array}{c}\alpha_{\mathrm{c}} \\
(\%)\end{array}$ \\
\hline \multirow{2}{*}{ Vane } & 0 & 88.2 & 93.3 & 112.8 & 113.98 & 38.90 \\
& 3.75 & - & 96.1 & 110.1 & 112.18 & 40.53 \\
\hline \multirow{2}{*}{ Screw } & 0 & 84.5 & 92.4 & 111.4 & 110.4 & 37.67 \\
& 3.75 & - & 92.6 & 109.7 & 105.9 & 38.04 \\
\hline
\end{tabular}

extruded by the vane extruder is a little lower than that extruded by the screw extruder.

The degree of crystallinity of pure LDPE and its composites was calculated (Table-2). The degrees of crystallinity for the pure LDPE and the samples with $3.75 \%$ weight content of nano- $\mathrm{CaCO}_{3}$ are 38.90 and $40.53 \%$, whereas they are 37.67 and $38.04 \%$ for the screw samples. It can be seen that, both for the vane and screw samples, the degree of crystallinity of the $\mathrm{LDPE} / \mathrm{CaCO}_{3}$ nanocomposites increases slightly with the presence of a few nano- $\mathrm{CaCO}_{3}$ content. Moreover, the degree of crystallinity of the vane samples is higher than that the screw samples. This may be due to that, suffered with continuous volume extensional flow and local chaotic flow, the nanocomposites have much smaller particle sizes and better dispersed distribution morphology.

Fig. 8 shows wide-angle X-ray diffraction (WAXD) patterns of $\mathrm{LDPE} / \mathrm{CaCO}_{3}$ nanocomposites with $3.75 \%$ weight content of nano- $\mathrm{CaCO}_{3}$. The curves are vertically offset for clarity. Compared with spectrum (a) of the screw samples, no new crystalline peak has been observed in spectrum (b) denoting no change in the crystalline form in the vane samples.

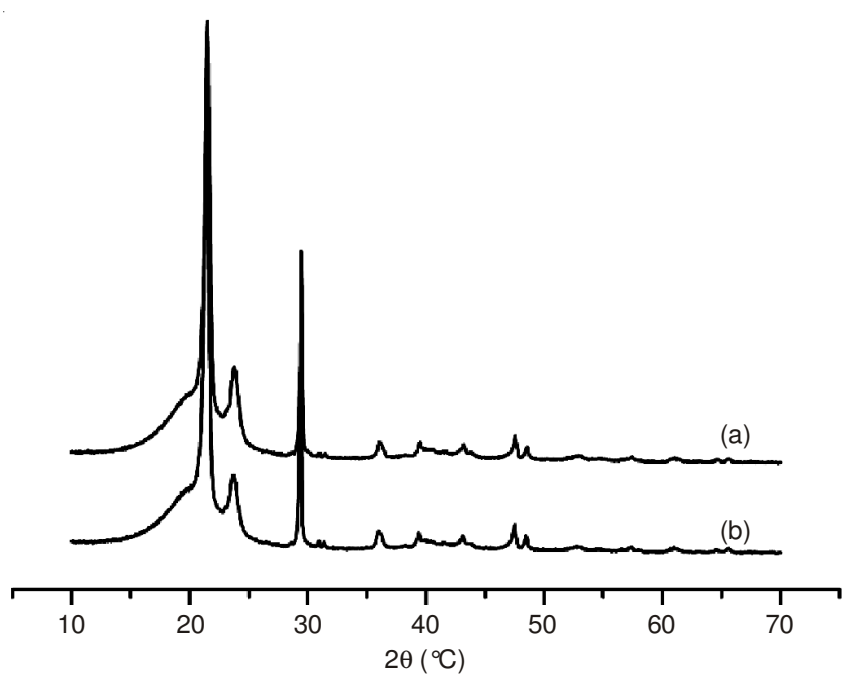

Fig. 8. Wide-angle X-ray diffraction (WAXD) patterns of $\mathrm{LDPE} / \mathrm{CaCO}_{3}$ nanocomposites: (a) Screw; (b) Vane

\section{Mechanical properties}

Tensile properties: Figs. 9-11 shows the tensile properties of the $\mathrm{LDPE} / \mathrm{CaCO}_{3}$ nanocomposites prepared both by the vane and screw extruder. It can be seen that all the tensile properties of the vane samples are higher than that of the screw samples, among which, the tensile strength of $\mathrm{LDPE} / \mathrm{CaCO}_{3}$ nanocomposites extruded by the vane extruder increases with the presence of a few nano- $\mathrm{CaCO}_{3}$, reaching a maximum when the content is $3.75 \%$, then decreases as the content of nano$\mathrm{CaCO}_{3}$ increases more. However, the tensile strength of LDPE/ $\mathrm{CaCO}_{3}$ nanocomposites extruded by the screw extruder always decreases with the content of $\mathrm{CaCO}_{3}$ increasing. The tensile modulus of the $\mathrm{LDPE} / \mathrm{CaCO}_{3}$ nanocomposites prepared both by the vane extruder and the screw extruder both increase with the rising of the content of $\mathrm{CaCO}_{3}$. The elongation at break of $\mathrm{LDPE} / \mathrm{CaCO}_{3}$ nanocomposites extruded by the vane extruder increases and then decreases with the increase of the content of $\mathrm{CaCO}_{3}$, reaching a maximum when the content is $3.75 \%$, similar with the trend of the tensile strength. However, it always decreases with the content of $\mathrm{CaCO}_{3}$ increasing for the screw extruder. It is suggested that the flow in vane extruder plays a role not only strengthening but also toughing $\mathrm{LDPE} / \mathrm{CaCO}_{3}$ nanocomposites. This may be due to the continuous volume extensional flow and local chaotic flow extruded nanocomposites has much fewer and smaller agglomerates that lead to be the breakage of the material, which can be seen in Fig. 12.

Moreover, the tensile properties of the pure LDPE prepared by the vane extruder are higher than that by the screw extruder. It may be due to two reasons. One is that the $\mathrm{L} / \mathrm{D}$ of the vane 


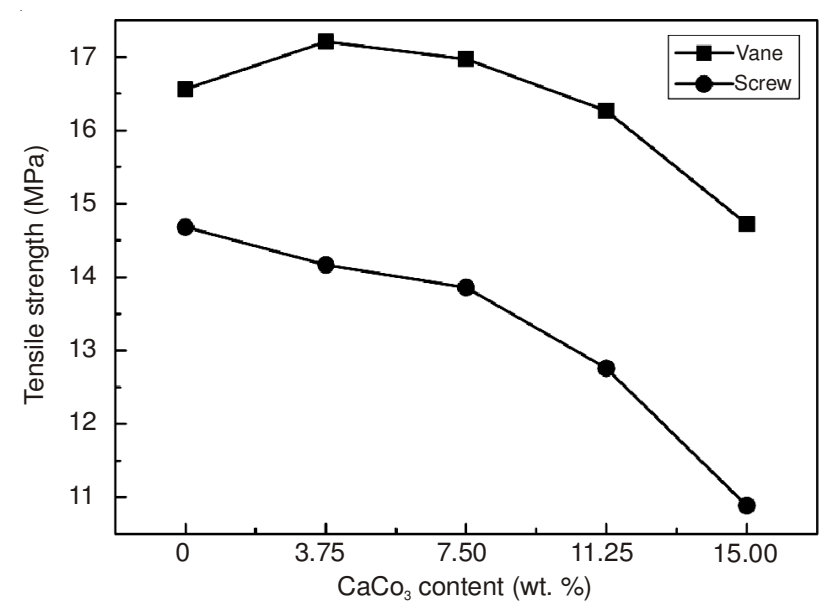

Fig. 9. Tensile strength of $\mathrm{LDPE} / \mathrm{CaCO}_{3}$ nanocomposites prepared by vane and screw extruders

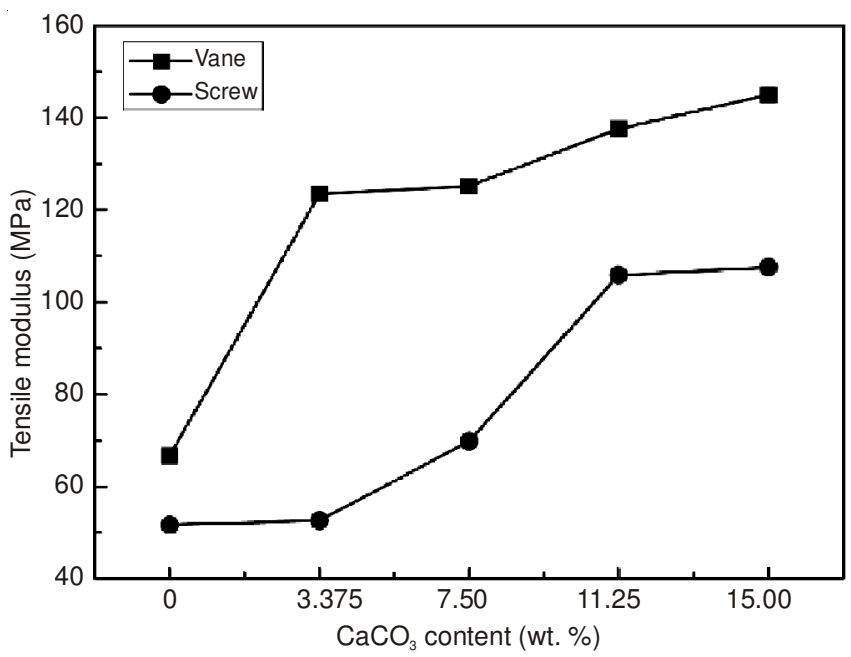

Fig. 10. Tensile modulus of $\mathrm{LDPE} / \mathrm{CaCO}_{3}$ nanocomposites prepared by vane and screw extruders

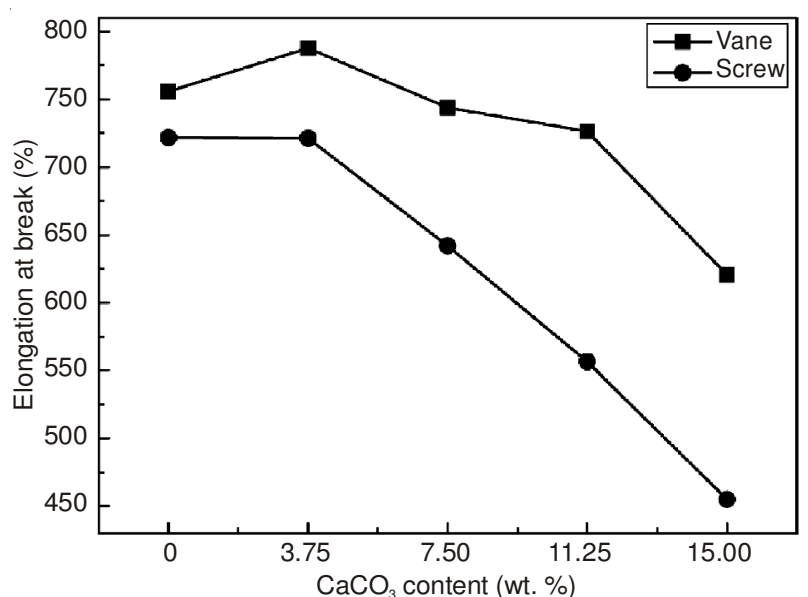

Fig. 11. Elongation at break of $\mathrm{LDPE} / \mathrm{CaCO}_{3}$ nanocomposites prepared by vane and screw extruders

vane extruder is shorter than that of the screw extruder, thus, the residence time of the materials in the vane extruder is shorter than in the extruder, which is $24 \mathrm{~s}$ at $120 \mathrm{r} / \mathrm{min}$ of the $\mathrm{LDPE} / \mathrm{CaCO}_{3}$ nanocomposites in the vane extruder and $75 \mathrm{~s}$ in the screw extruder. The shorter residence time leads to less degradation of the molecular weight of LDPE. Another is the extensional flow is better for the crystal behaviours.

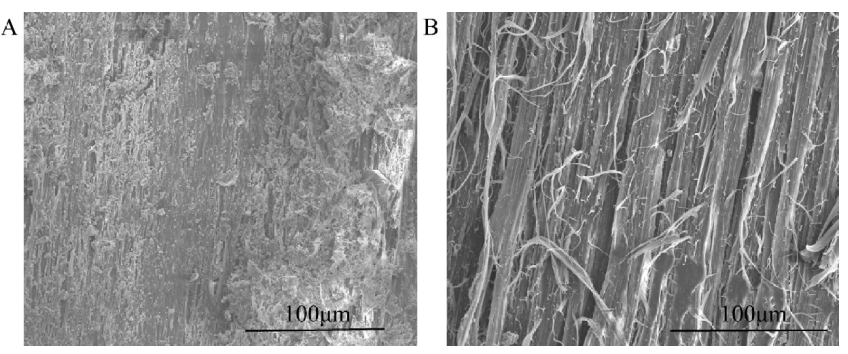

Fig. 12. SEM micrographs of tenslie surfaces of LDPE/11.25\% $\mathrm{CaCO}_{3}$ nanocomposites (A) Screw; (B)Vane

Flexural properties: Figs. 13 and 14 show the flexural properties of $\mathrm{LDPE} / \mathrm{CaCO}_{3}$ nanocomposites prepared both by the vane extruder and the screw extruder. It can be seen that all the flexural properties of the $\mathrm{LDPE} / \mathrm{CaCO}_{3}$ nanocomposites extruded by the vane extruder are higher than that by the screw extruder. The flexural strength and modulus of the LDPE/ $\mathrm{CaCO}_{3}$ nanocomposites both increase with the increasing content of $\mathrm{CaCO}_{3}$ neither prepared by the vane extruder or by the screw extruder. The greater flexural properties are attributed to the good distribution and dispersion effects of the continuous volume extensional flow and local chaotic flow in the vane extruder.

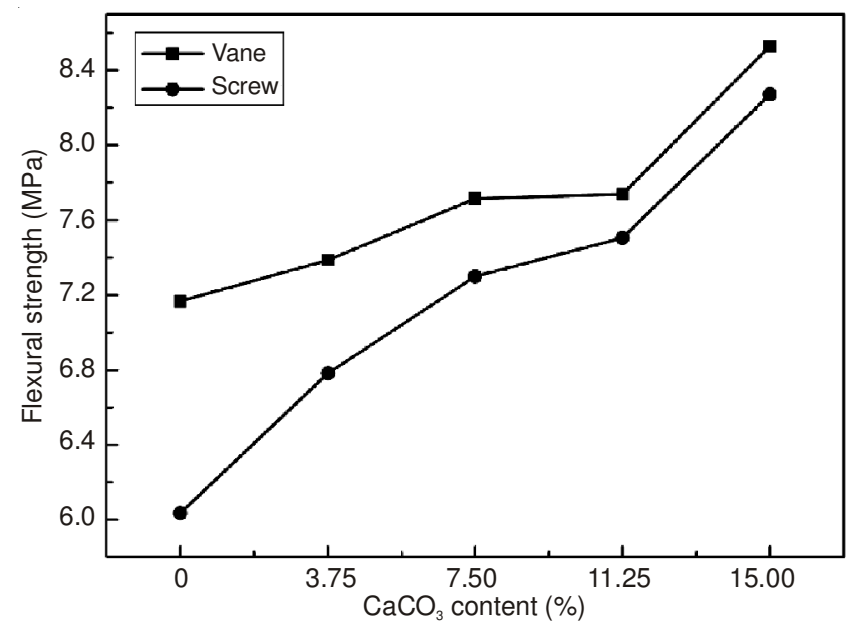

Fig. 13. Flexural strength of $\mathrm{LDPE} / \mathrm{CaCO}_{3}$ nanocomposites prepared by vane and screw extruders

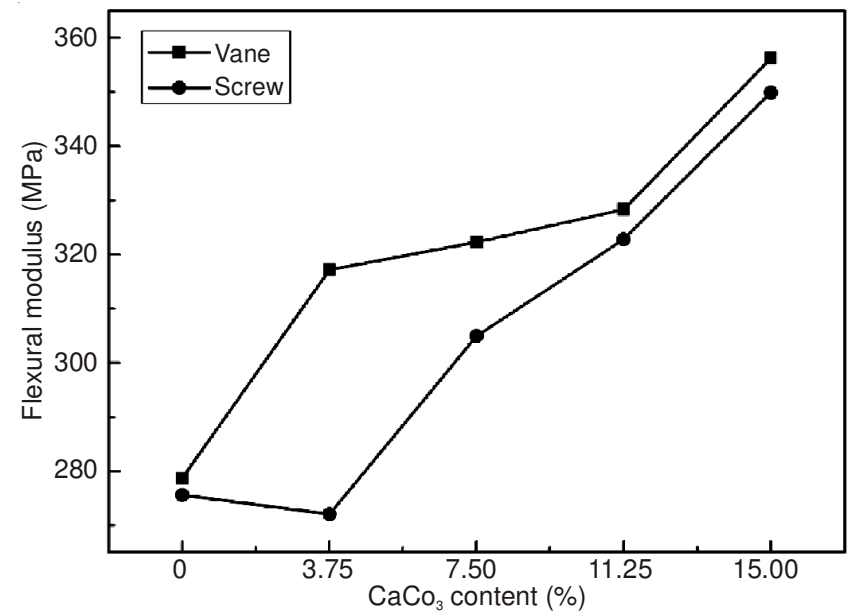

Fig. 14. Flexural modulus of $\mathrm{LDPE} / \mathrm{CaCO}_{3}$ nanocomposites prepared by vane and screw extruders 


\section{Conclusion}

The vane extruder is a kind of novel equipment for polymer processing, which can generate a continuous volume extensional flow and a local chaotic flow. Effects of the flow on the structure and mechanical properties of the $\mathrm{LDPE} / \mathrm{CaCO}_{3}$ nanocomposites have been investigated using the vane and screw extruders. The extensional flow in the whole extrusion process can effectively improve the dispersion of the nanoparticles in the LDPE matrix, leading to a smaller particle size and better effects on the distribution and dispersion mixing. Compared with the screw extruded sample, the vane extruded $\mathrm{LDPE} / \mathrm{CaCO}_{3}$ nanocomposites have higher degree of crystallinity. Consequently, they exhibit better tensile and flexural properties.

\section{ACKNOWLEDGEMENTS}

The authors acknowledged the National Nature Science Foundation of China (Grant 10872071, 50973035, 50903033, 51073061 and 21174044), National Key Technology R \& D Program of China (Grant 2009BAI84B05 and 2009BAI84B06), the Fundamental Research Funds for the Central Univer- sities (No. 2012ZM0047), Program for New Century Excellent Talents in University (No.NCET-11-0152), Pearl River Talent Fund for Young Sci-Tech Researchers of Guangzhou City (No.2011J2200058), 973 Program (No. 2012CB025902) and National Natural Science Foundation of China-Guangdong Joint Fundation Project (U1201242) for the financial supports.

\section{REFERENCES}

1. Y. Gao and L. Liu and Z. Zhang, Acta Mechan. Solida Sin., 22, 555 (2009).

2. Y.F. Xiang, Polym. Adv. Technol., 21, 48 (2010).

3. H.-Z. He and J.-X. Fu, Modern Plastics Proces. Appl., 20, 1 (2008).

4. G. Wang, China Plastic Chengdu: Sichuan Univ., 10, 23 (2003).

5. F.N. Fritsch and R.E. Carlson, SIAM J. Numer. Anal., 17, 238 (1980).

6. J.G. Ryu, H. Kim and J.W. Lee, Polym. Eng. Sci., 44, 1198 (2004).

7. E.C. Lee, D.F. Mielewski and R.J. Baird, Polym. Eng. Sci., 44, 1773 (2004).

8. M. Arellano, I. Manas-Zlocaower and D.L. Feke, Polym. Compos., 16, 489 (1995)

9. M. Tokihisa, K. Yakemoto, T. Sakai, L.A. Utracki, M. Sepehr, J. Li and Y. Simard, Polym. Eng. Sci., 46, 1040 (2006).

10. H.C. Kim, A. Pendse and J.R. Collier, J. Rheol., 38, 831 (1994).

11. J.P. Qu, China Patent 200810026054.X (2008).

12. J.P. Qu, Eng. Sci., 10, 20 (2012). 